\title{
ELEMENT CONSTITUENTS OF RODENT BULBOURETHRAL GLAND GOBLET GRANULES, VERTEBRATE MAST GELL GRANULES AND HUMAN PLATELET DENSE BODIES BY QUANTITATIVE X-RAY MICROANALYSIS ON FRESH PREPARATIONS
}

\author{
${ }^{*}$ Kenighi TAKAYA, ${ }^{* *}$ KenjI NIIYA, ${ }^{* * *}$ Tohru MASUDA \\ AND ${ }^{* * * *}$ MASAHIKO TOYODA
}
Department of ${ }^{*}$ Anatomy, ${ }^{* *}$ Clinical Laboratory Medicine, ${ }^{* * *}$ Anesthesiology and ${ }^{* * * *}$ Dermatology, Toyama Medical and Pharmaceutical University, 2630 Sugitani, Toyama 930-01

Fresh preparations including fresh frozen dried ultrathin sections, prints and smears and fresh airdried prints and smears were prepared of the rat, hamster and guinea pig bulbourethral glands (BUG), tree frog tongue, red ear turtule blood and goldfish intestine and adult normal and allergic dermatitis and chronic myelogenous leukemia patient blood. They were observed under a $200 \mathrm{kV}$ transmission electron microscope at acceleration voltages of $200 \mathrm{kV}$ and $80 \mathrm{kV}$. They were then observed under the analytical electron microscope (AEM, X-650) in a scanning transmission (STEM) mode at an acceleration voltage of $40 \mathrm{kV}$ at specimen currents of $0.2,1$ and $2 \mathrm{nA}$. Goblet cell granules, mast cell and basophil granules and platelet dense bodies were analyzed under AEM in a STEM mode at an acceleration voltage of $40 \mathrm{kV}$, specimen current of 1 or $2 \mathrm{nA}$, counting time of $100 \mathrm{sec}$. The quantification was made using a program prepared by the standard solution of $20 \%$ polyvinylpyrollidone containing different kinds of compounds of 16 different elements. The concentration was expressed in $\mathrm{mM} / \mathrm{KG}$ dry weight. In the fresh frozen dried ultrathin sections prepared by a new freezing method with a microwave, the areas extending up to $100 \mu \mathrm{m}$ deep from the specimen surface were free from ice-crystal artifacts and the limiting membrane of the goblet granules were distinctly recognized surrounding the individual granules. A quantitative X-ray microanalysis (QXMA) revealed that goblet cell granules of the rat, hamster and guinea pig BUG contained high concentrations of sulfur and magnesium and small amounts of calcium and sulfur and magnesium showed close positive correlations in their concentration. Among forty nine mucous granules of the rat BUG cryofixed with microwave, most contained high concentrations of sulfur and magnesium while a few had high concentrations of sulfur and potassium and small amounts of magnesium or calcium. QXMA of mast cell granules of the tree frog tongue, spleen and peritoneum on fresh frozen dried ultrathin sections, fresh frozen dried and fresh air-dried prints, red ear turtle blood basophils on fresh air-dried smears and goldfish small intestine on fresh frozen dried ultrathin sections disclosed high concentrations of sulfur and magnesium in tree frog mast cell and basophil granules, large amounts of zinc in goldfish intestine mast cell granules while basophil granules of the turtle blood contained high concentrations of sulfur and a very small amount of magnesium or calcium. QXMA of human blood platelet dense bodies revealed high concentration of phosphorus and calcium and very small amounts of magnesium in all the persons examined except one $\mathrm{AD}$ and one $\mathrm{CML}$ patient whose platelet dense bodies contained high concentrations of magnesium. Divalent cations in mast cells are probably in close relation with proteoglycans, those in goblet cell granules with glycoproteins and those in platelet dense bodies bound to nucleotides such as ATP and ADP within the granules respectively.

This research was supported by a grant from the Ministry of Education, Science, and Culture, JAPAN, No. 01570005.

Presented in prat at the symposium 1 on Advances in
Cytochemistry with Physical Method, July 13, 1944 as part of the program at the 4th Jiont Meeting of the Japan Society of Histochemistry and Cytochemistry and the Histochemical Society, held in Maui, Hawaii, July 13 to 16, 1994. 

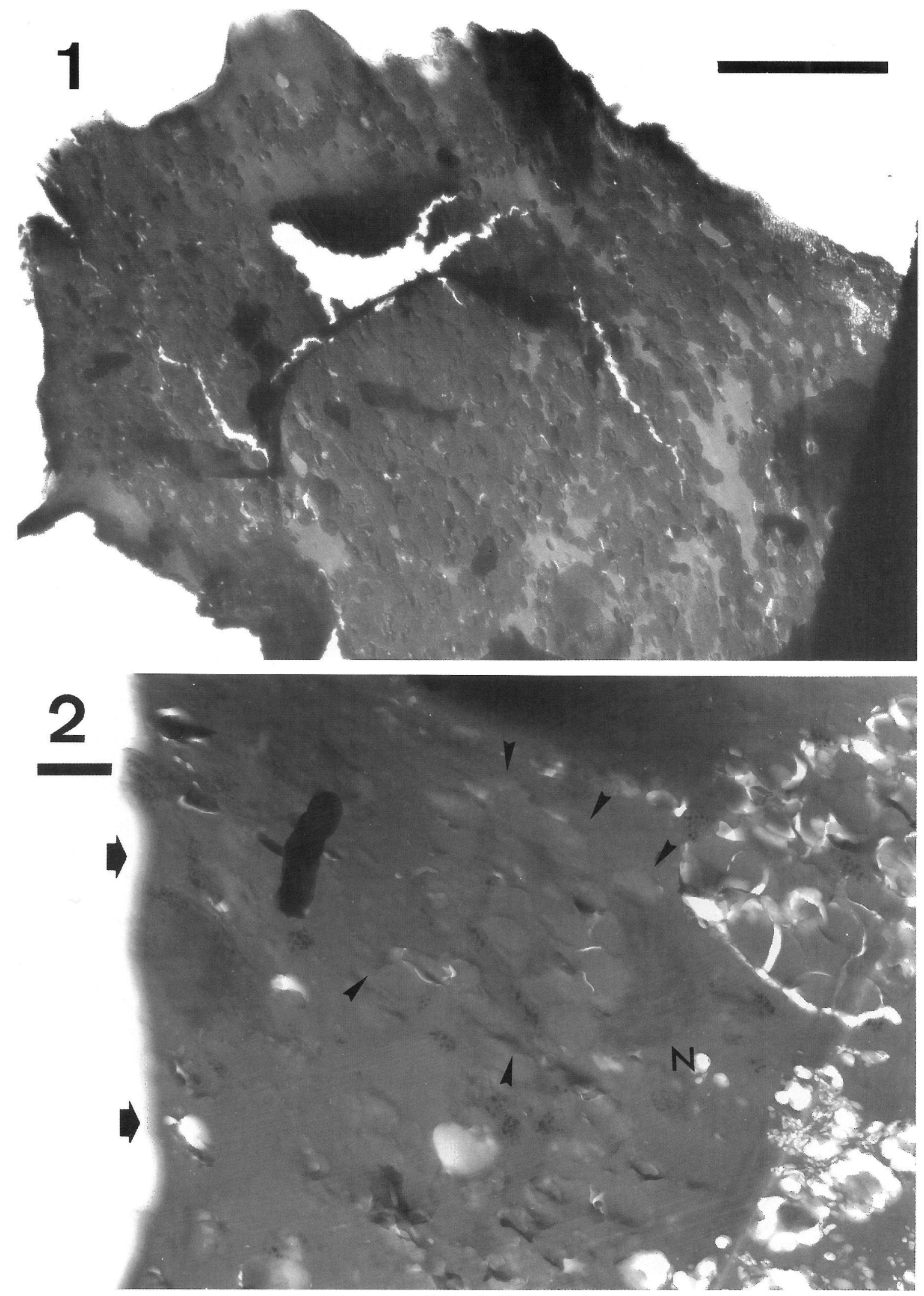

Figs. 1, 2. 
We have been working with the fresh preparations for elemental constituents of cells and tissues at fine structural level by a quantitative X-ray microanalysis. The fresh preparations consist of fresh frozen dried ultrathin sections (6), fresh frozen dried prints (13) and smears (16), fresh air-dried cryostat sections (12), fresh air-dried prints (7) and smears (13). We are using chiefly fresh frozen dried ultrathin sections, but occasionally other specimens for the brevity and simplicity of their preparations. We reported the detection of several elements in different kinds of secretory granules. Elements detected were sodium, magnesium, phosphorus, sulfur, chloride, potassium, calcium and iron. Detection of calcium and magnesium in the granules of pancreatic acinar cells, platelet, melanocyte and mast cells was reported in the symposium of this society and it was published in this journal in 1979 (7). Thereafter, we have been trying to quantificate the elemental contents and emphasizing the magnesium contents in fine structures of the cells and tissues $(8,9,10,11)$. In this symposium I am going to mention the elemental composition of goblet cell granules, mast cells and platelet dense bodies of several vertebrate species and the relationships among these elements in their concentration. A cryofixation technique is introduced for the preparation of a better fresh frozen dried ultrathin sections.

\section{MATERIALS AND METHODS}

As materials, use was made of the bulbourethral gland of the rat, guinea pig and hamster, the tongue, spleen and peritoneum of the tree frog and goldfish intestine and blood of normal persons and patients of atopic dermatitis and chronic myelogenous leukemia.

\section{Specimen preparation}

Fresh frozen dried ultrathin sections were prepared by a new technique of cryofixation in the microwave oven. Fresh tissue fragments were attached on the aluminum chuck and hung with a thread from the hole in the center of the oven chamber using a Toshiba microwave oven, Model ER-360 S(N), frequency $2450 \mathrm{MHz}$ with $500 \mathrm{Watt}$ power source. The specimen was irradiated in the oven chamber at a power setting of strong for $2-10 \mathrm{sec}$ followed by dipping the specimen on the chuck into liquid nitrogen or the Daifron 13 prechilled with liquid nitrogen.

Frozen sections were made by cryosectioning apparatus attached to the ultramicrotome (MT2-B, Sorvall) at $60 \mathrm{~nm}$ in thickness, pressed onto the collodion film covered titanium grids and put in the copper net cage which was fixed in the specimen holder of frozen specimen treatment apparatus (FD-2A, Hitachi). The holder was transferred into the chamber of FD-2A and dried in a high vacuum. The freeze-dried sections on the grids were stored in plastic bottles containing silica gel (13).

Tissue prints were prepared by cutting the specimen with a safety razor knife and the cut surface was made to have light contact with the collodion film over the titanium grids. Some were cryofixed in Daifron 13 prechilled with liquid nitrogen and freezedried at a high vacuum. Others were air-dried after the contact.

Smears of the blood and buffy coat were prepared by putting a drop of the blood or the coat on the collodion film covering titanium grids. The blood was immediately wiped away with a piece of filter paper which had been warmed on the electric warmer immediately before use. some smears were dipped in Daifron 13 prechilled with liquid nitrogen and freezedried in a high vacuum. Others were air-dried.

\section{Electron microscopy and $X$-ray microanalysis}

Transmission electron microscopy was performed under the $200 \mathrm{kV}$ electron microscope (JEM-200CX) at acceleration voltages of $200 \mathrm{kV}$ and $80 \mathrm{kV}$. Scanning transmission electron microscopy (STEM) was made under an analytical electron microscope (X-650, Hitachi) at an acceleration voltage of $40 \mathrm{kV}$ at specimen currents of $0.2,1$ and $2 \mathrm{nA}$.

FIG. 1. $200 \mathrm{kV}$ Transmission electron micrograph (TEM) of a fresh frozen dried ultrathin section of the rat bulbourethral gland (BUG) prepared by ctyofixation with microwave irradiation for $2 \mathrm{sec}$ and dipping into the Daifron 13 prechilled with liquid nitrogen within the microwave oven. The large area from the surface of the specimen was free from ice-crystal artifacts. There are several ruptures in the section which are probably due to the pressure during the pressing of the sections onto the copper grid whose bars were covered with collodion film by a mucous treatment. $\times 2,900 \quad \mathrm{Bar}=10 \mu \mathrm{m}$

Fig. 2. $200 \mathrm{kV}$ TEM of a fresh frozen dried ultrathin section of the rat BUG prepared by cryofixation with microwave irradiation for $5 \mathrm{sec}$ and dipping into liquid nitrogen within the oven. The area more than $10 \mu \mathrm{m}$ deep from the surface of the specimen (arrows) is free from ice-crystal artifacts. The area deeper than $10 \mu \mathrm{m}$ has many artifacts probably due to the ice-crystal formation. The arrow heads indicate a mucous cell with a nucleus $(\mathrm{N})$ and abundant mucous granules filling the cytoplasm of the cell. $\times 12,200 \quad \mathrm{Bar}=1 \mu \mathrm{m}$ 
Electron probe X-ray microanalysis was carried out under the AEM (X-650) with an energy dispersive spectrometer (Kevex-7000) in a STEM mode. Point analysis was made at specimen currents of 1 and $2 \mathrm{nA}$, counting time of $100 \mathrm{sec}$ at a magnification of 10,000 . The X-ray counts were calculated with a quantification program using a continuum normalization method of Hall (1). The concentration was expressed in $\mathrm{mM} / \mathrm{KG}$ dry weight (10).

\section{RESULTS}

Transmission electron microscopy (TEM) of fresh frozen dried ultrathin sections of the rat bulbourethral gland at acceleration voltages of 200 and $80 \mathrm{kV}$ disclosed wide ice-crystal free area extending over $100 \mu \mathrm{m}$ in diameter and depth from the surface of the specimens which were cryofixed into a daifron 13 prechilled with liquid nitrogen (Fig. 1) and over $10 \mu \mathrm{m}$ from the surface of the specimens which was cryofixed into the liquid nitrogen (Fig. 2). In the latter, a goblet cells was found to be full of mucous granules. They appeared homogeneously clear. In a higher magnification individual granules was surrounded by a plasma membrane and no fusion of the granules was recognized (Fig. 3) as was reported by the freeze-substitution technique (3) and microwave fixation in the conventional chemical fixatives (4). The nucleus surrounded by a nuclear membrane was devoid of ice-crystal artifacts. TEM of the tree frog tongue, spleen and peritoneum on fresh frozen dried and fresh air-dried prints disclosed mast cells containing abundant granules in which the dense crystalloid core was found (11). Blood of red ear turtle contained many basophils. A large number of mast cells were found in the submucosa of gold fish intestine. Individual granules were recognized under TEM. TEM of fresh frozen dried ultrathin sections and fresh frozen dried and fresh air-dried smears of human blood and buffy coat of heparinized blood revealed platelet showing

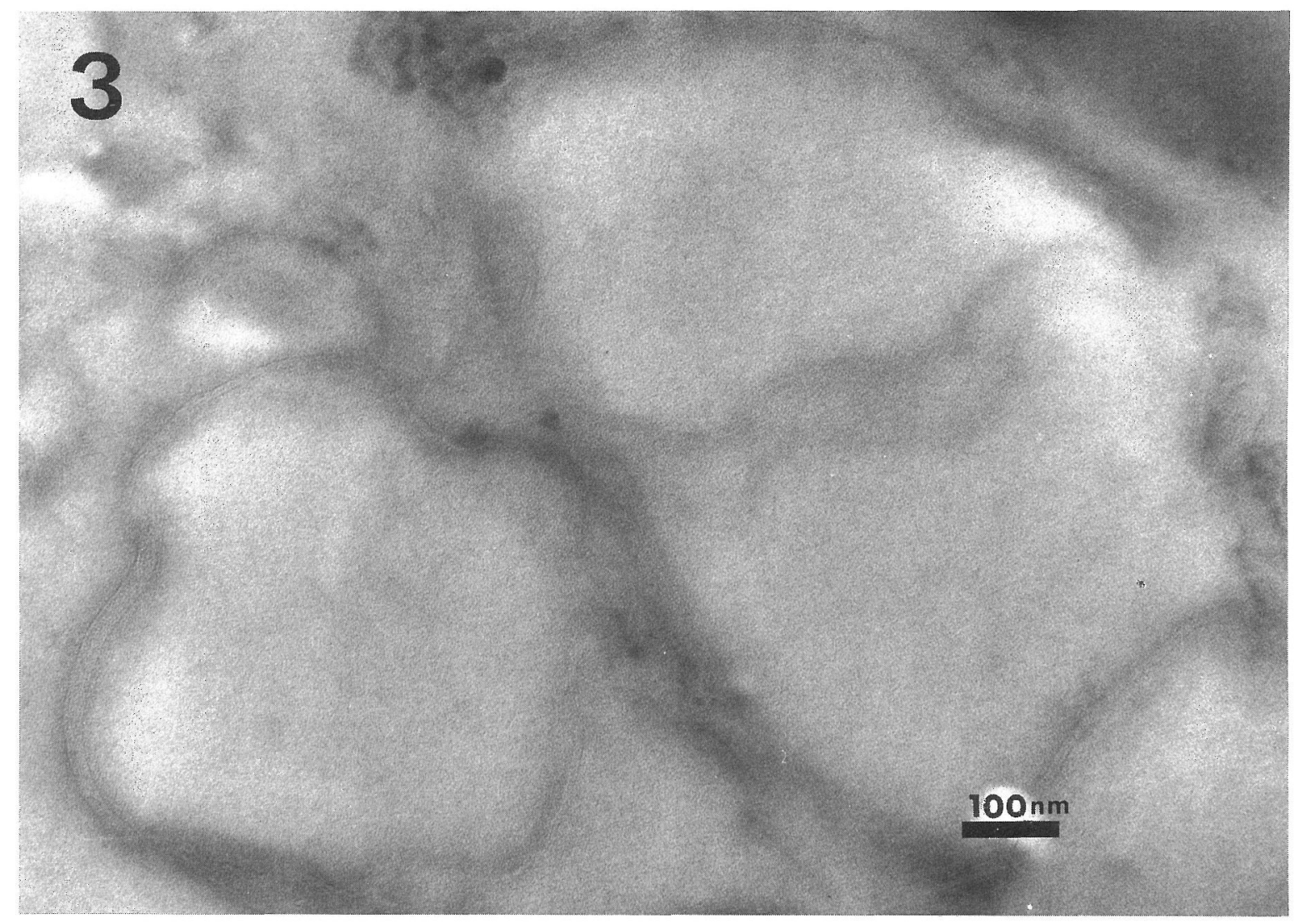

FIG. 3. A higher magnification of a region of granules of the mucous cell as shown in Fig. 2. The individual granules are srrounded by the limiting membrane. The granule content is homogenous which has some irregularities, but not so apparent in this magnification. $\times 117,900 \quad B a r=100 \mathrm{~nm}$ 


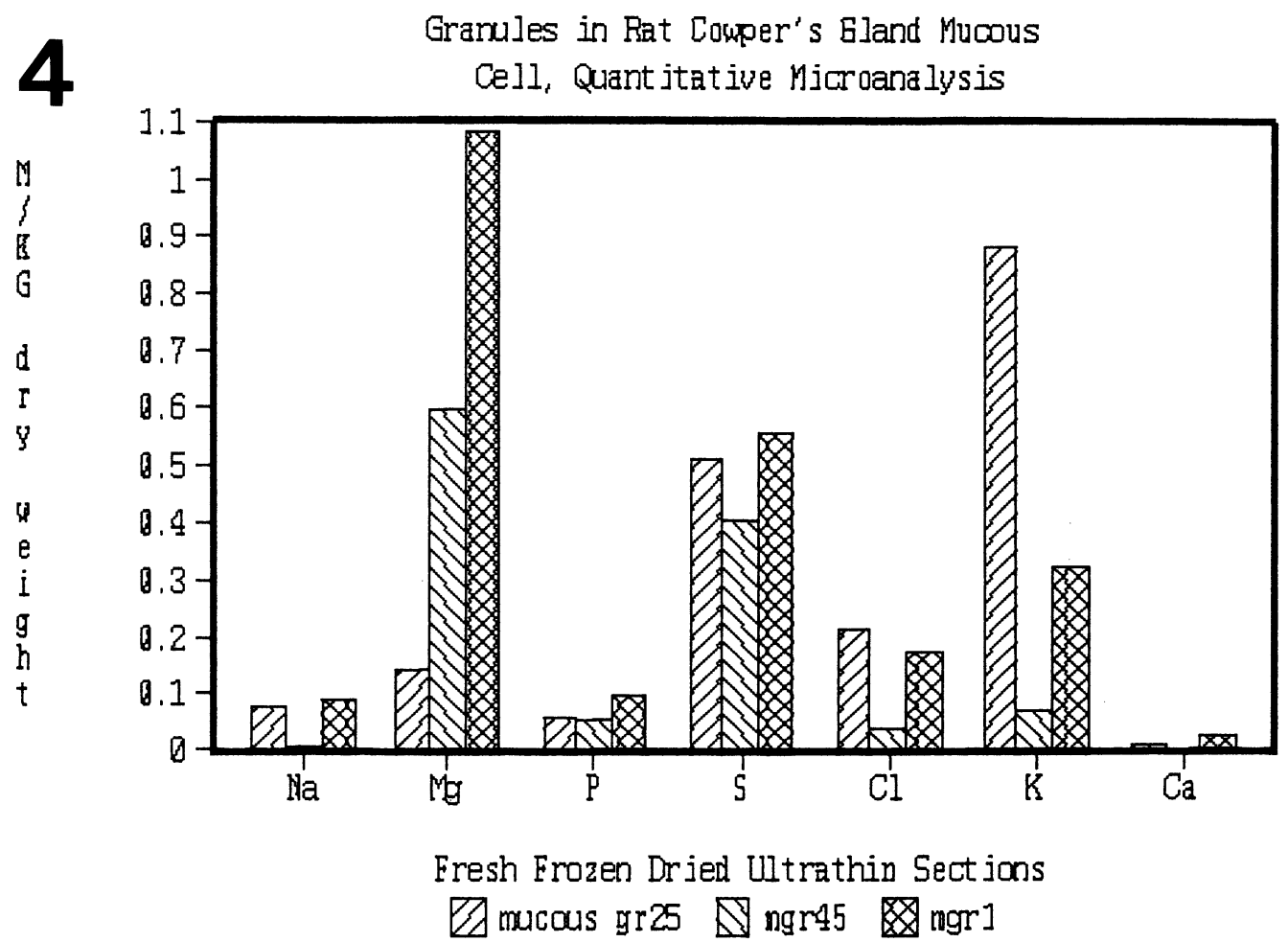

Fig. 4. A graph showing the element constituents of three representative granules of 49 mucous granules of the mucous cell as is shown in Fig. 2. and Fig. 3. which were examined by a quantitative X-ray microanalysis using a continuum normalization method. Most granules contain large amounts of magnesium and sulfur as the mucous granule 45 (mgr45) and the mucous granule 1 (mgr1). Only four granules contain high concentrations of sulfur and potassium and small amounts of magnesium and calcium as the mucous granule 25 (mucous gr25).

TABLE 1. Magnesium, phosphorus and calcium concentration and magnesium to calcium ratios of the platelet dense bodies of human blood from nine normal persons, four atopic dermatitis $(A D)$ and two chronic myelogenous leukemia (CML) patients

(mean, mM/KG dry weight)

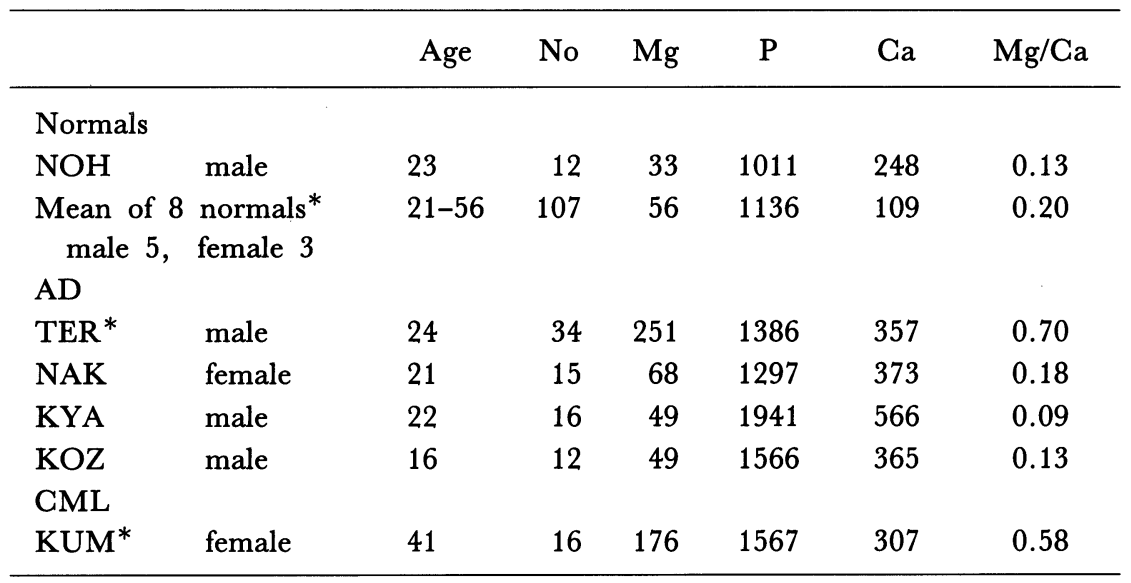

*published in (15). 
dense bodies and alpha granules $(5,14-16)$. The fine structures especially the granules as observed by TEM were recognized by STEM under the AEM.

QXMA of the mucous granules of the Cowper's gland of the rat, hamster and guinea pig both in the fresh air-dried spread and fresh frozen dried ultrathin sections revealed large amounts of sulfur and magnesium and small amounts of calcium in those of the guinea pig (13). QXMA of 49 mucous granules of the rat Cowper's gland on fresh frozen dried ultrathin sections showed they contain high concentrations of sulfur. Most granules contained high concentrations of sulfur and magnesium but a few had large amounts of sulfur and potassium and small amounts of magnesium (Fig. 4). QXMA of human platelet dense bodies of eight normal, four atopic dermatitis and two chronic myelogenous leukemia patients indicated high concentrations of phosphorus and calcium. Only the dense bodies of one AD and one CML patients contained high concentrations of magnesium as well as phosphorus and calcium (Table 1).

\section{DISCUSSION}

Microwave irradiation was successfully applied to the cryofixation of animal tissues for freeze-substitution which permitted the preservation of the fine structures over 100 um deep from the surface of the specimens which were made in contact with the metal surface prechilled with liquid nitrogen (2).

It is assumed that magnesium and calcium are bound with nucleotides such as ATP and ADP in the dense bodies of the human platelet, to proteoglycans in mast cell granules and glycoproteins in mucous cell granules. Relative concentration of magnesium and calcium in the granules examined has some tendencies in different organs and tissues of various animal species. It is interesting that the magnesium concentration is high in mast cell and basophil granules of the frog and zinc content is high in goldfish intestine mast cells. Mast cells of the mammals, birds and reptiles have histamine in their granules while the amphibian and fish, in the mast cells and basophils. Divalent cations may be present in place of histamine in those granules, although the function is unclear (11).

It was also clarified in some clinical conditions the tendency was changed although the mechanism was not clear. As was reported previously (9), the platelet dense bodies of the human and monkey contain high concentrations of phosphorus and calcium and little magnesium while those of the rat, guinea pig, mouse and cat had large amounts of magnesium, calcium and phosphorus. Large amounts of magnesium in the platelet dense bodies as revealed in one $\mathrm{AD}$ and one CML patients should be stressed because they may give a clue to clarify the mechanism of storage of large amounts of magnesium in the patients and some other mammals. Most interesting is the finding of high concentrations of magnesium in platelet dense bodies in two patients which is more common in rodent platelet dense bodies. Further examination of the granules in different organs and species will clarify the meconium and function of cations in the granules.

\section{REFERENCES}

1. Hall, T. A. and Gupta, B. L.: Quantitation for the Xray microanalysis of cryosections. J. Microsc. 126; 333$345,1982$.

2. Hamyu, Y., Ichikawa, M. and Matsumoto, G.: A novel method of rapid freezing in biological electron microscopy. J. Electron Microsc. 39; 349, 1990.

3. Ichikawa, M. and Ichikawa, A.: The fine structure of sublingual gland acinar cells of the Mongolian gerbil, Meriones unguiculatus, processed by rapid freezing followed by freeze-substitution fixation. Cell Tiss. Res. 250; 305$314,1987$.

4. Mizuhira, V., Hasegawa, H. and Notya, H.: Microwave fixation for histo and cytochemistry. In "Electron Microscopic Cytochemistry and Immunocytochemistry in Biomedicine", ed. by $\mathrm{K}$. Ogawa and $\mathrm{T}$. Barka, CRC Press, N. W. Fl., 1993, pp. 17-27.

5. Takaya, K.: Electron probe microanalysis of the dense bodies of human blood platelet. Arch histol. japon. 37; 335-341, 1975.

6. Takaya, K.: Preparation of fresh frozen dried ultrathin sections by drying without vacuum. Acta anat. 96; 248258, 1976.

7. Takaya, K.: X-ray microanalysis using unstained, fresh air-dried tissue spreads. Calcium and magnesium in the granules of pancreatic acinar cells, platelet, malanocytes and mast cells. Acta Histochem. Cytochem. 12; 237-240, 1979.

8. Takaya, K.: Electron microscopy of unstained, fresh airdried spreads of the mouse brain and application to energy dispersive X-ray microanalysis. Arch. histol. japon. 42; 533-542, 1979.

9. Takaya, K.: X-ray microsnalysis of biological materials using unfixed specimens. Seitainokagaku 34; 137-142, 1983.

10. Takaya, K.: Elemental composition of mast cell granules of the rat and tree frog; X-ray microanalysis on fresh frozen dried ultrathin sections. Electron Microscopy 3; 356357, 1990.

11. Takaya, K.: Magnesium and sulfur in mast cell and basophil granule $\mathbf{s}$ of lower vertebrates in relation with histamine. Electron Miroscopy 2; 1596-1957, 1992.

12. Takaya, K.: Quantitative X-ray microanalysis of zinc on fresh cryostat sections. Acta Anat. Nippon. 69; 470, 1994. 
13. Takaya, K. and Masuda, T.: Quantitative X-ray microanalysis of biological materials on freeze-dried stamps and fresh frozen dried ultrathin sections. J. Clin. Electron Microscopy: 24; 445-446, 1991.

14. Takaya, K. and Niiya, K.: Small dense granules in human platelet of normal and storage pool deficiency blood on fresh air-dried smear-200 kV STEM and EDS $\mathrm{X}$-ray microanalysis. Program of Second Japan-Korea Anatomical Joint Meeting Tokyo Seminar 1990, 129$130,1990$.
15. Takaya, K., Niiya, K., Toyoda, M. and Masuda, T.: High magnesium concentrations in the dense bodies of human blood platelet from patients with atopic dermatitis and chronic myelogenous leukemia. J. Clin. Electr. Microsc. in press.

16. Takaya, K., Toyoda, M. and Masuda, T.: Element constituents of platelet dense bodies of human blood by a quantitative $\mathrm{X}$-ray microanalysis on fresh air-dried smears. Program of the 4th Japan-Korea Anatomical Joint Meeting Yamagata Seminar 1994, 27-28, 1994. 